\title{
Crowd-Powered Mechanisms for Viewing and Imagining Public Spaces
}

\author{
Shin'ichi Konomi $^{1}$ Tomoyo Sasao $^{2}$ Wataru Ohno ${ }^{2}$ Kenta Shoji $^{2}$ \\ ${ }^{1}$ Center for Spatial Information Science, the University of Tokyo \\ ${ }^{2}$ Graduate School of Frontier Sciences, the University of Tokyo
}

\begin{abstract}
Crowdsourcing allows one to collect information from a large number of citizens relatively easily, thereby creating an opportunity to provide a novel technological means to view and imagine the city, complementing conventional geovisualization and urban simulation games. We postulate that the inflexibility of existing crowdsourcing frameworks can impose inherent limitations in terms of the imaginability of the city, and propose citizensourcing, which augments crowdsourcing with the mechanisms for supporting exploration and active participation in order to address the limitations. We then describe our experiences with the smartphone-based prototypes of the mechanisms, and discuss their implications for the design of citizensourcing environments.
\end{abstract}

Keywords: Crowdsourcing, collaboration, geo-visualization, public spaces

\section{Introduction}

Visualization and interaction technologies provide citizens with powerful means to view the world around them in ways that are impossible with naked eyes. Moreover, they can enhance people's ability to imagine what cannot be seen, including possible future scenarios, about cities and public spaces.

Physical and digital maps, for example, provide a means to grasp spatial patterns at different scales, and GIS (Geographic Information Systems) exploit various information processing and visualization methods to keep track of events, activities, and things along with their locations. Moreover, urban simulation games have been used in urban planning contexts [11]. For example, the EDC system [1] allows stakeholders to interact with a simulation environment on a digital map using a tangible user interface, thereby allowing for experimentation with decisions and negotiations.

In recent years, crowdsourcing emerged as a powerful means to collect and analyze urban data, as it allows one to organize micro and macro labor of a large crowd of citizens relatively easily. Crowdsourcers can ask crowdworkers to collect and analyze information about urban and public spaces on demand, however, the task requests have to be prescribed with rigid instructions. This makes many of the existing crowdsourcing frameworks inherently inflexible, which makes it extremely difficult to explore and discover novel, possibly imagination-enhancing information.

This paper proposes an approach called citizensourcing. We focus on this approach to address the inherent inflexibility of crowdsourcing and develop a novel crowd-powered mechanism for viewing and imagining urban and public spaces. Citizensourcing can be considered as a public space-centric collaboration space for crowds, which augments crowdsourcing with the mechanisms for 
supporting awareness, active participation, exploration, and end-user development. We also discuss the design of citizensourcing environments based on our experiences with three smartphone-based prototype tools.

\section{Crowdsourcing}

Crowdsourcing is a means of organizing and coordinating the labor of individual human beings, and often exploits information communication technologies to contact individuals, offer them things to do and collect the results of their work.

Crowdsourcing has various ramifications in the ways people use spatial data and relevant social practices [4], and researchers have discussed its potential in mobile, pervasive and urban environments [12][20]. Creek Watch, for example, allows citizens to collect useful environmental information related to water and trash management using smartphones [6]. Common Sense Community supports local community members to collect and make sense of air quality data [17]. Willett et al. discuss strategies for improving crowdsourced data analysis as well [18].

Crowdsourcing is often used for simple, independent tasks. Workflow-based approaches can be used to handle more complex tasks [7][10]. However, existing crowdsourcing frameworks assume static and inflexible workflows, which makes it difficult to support exploratory data collection and analysis. This limitation could trivialize the impact of crowdsourcing technologies in urban spaces since many of the real-world, societal problems in a city can be considered ill-structured, 'wicked' problems [14] that one cannot simply "first understand, then solve." Coping with such problems can require a more open-ended, exploratory data collection and analysis environment based on situated actions [15], which considers different perspectives of participants and supports continuous and opportunistic processes.

Without a systematic support mechanism for exploration and collaboration, crowdsourced information could only be useful for reinforcing preconceived understanding or ideas. This significantly limits the potential of crowdsourcing to discover innovative solutions in a collective manner.

\section{Citizensourcing}

To make crowdsourcing more useful as a novel social information environment for urban and public spaces, we consider the difference of globally distributed workflows and locally relevant workspaces. Micro-tasking crowdsourcing services such as Mechanical Turk [13] support workflows to coordinate distributed workers who are located somewhere in the world. As citizens often focus their attention on their local environments, we propose citizensourcing, an approach to supporting locally-relevant crowdsourcing based on communities of practice [16].

Citizensourcing can support awareness, communication, coordination, exploration and reflection in different ways from globally distributed crowdsourcing. Some workers may be connected from afar, but it is inseparable from the local concerns of a public space.

Table 1 describes citizensourcing based on the three components for supporting crowdsourcing practice: engagement, imagination, and alignment. Firstly, engagement of crowdworkers can be supported by communication facilities such as online forums. In citizensourcing, it can be supported by location-based in situ awareness tools and geo-tagged repositories of community-relevant information. Secondly, imagination of crowdworkers refers to the process to encompass and deal with a broader context, and it can be 
supported by in situ exploration and reflection tools such as mobile visualization interface. Finally, alignment of crowdworkers concerns common focus and coordination. Task instructions can create common focus in crowdsourcing, whereas in situ communication and awareness tools can be used to support alignment in citizensourcing.

\begin{tabular}{|l|l|l|}
\hline & Crowdsourcing & Citizensourcing \\
\hline $\begin{array}{l}\text { Support for } \\
\text { Engagement }\end{array}$ & - Online forum & $\begin{array}{l}\text { - In situ aware- } \\
\text { ness tool } \\
\text { - Repositories } \\
\text { of community } \\
\text { relevant infor- } \\
\text { mation }\end{array}$ \\
\hline $\begin{array}{l}\text { Support for } \\
\text { Imagination }\end{array}$ & $\begin{array}{l}\text { (No direct sup- } \\
\text { port) }\end{array}$ & $\begin{array}{l}\text { - In situ explo- } \\
\text { ration tool } \\
\text { - In situ reflec- } \\
\text { tion tool }\end{array}$ \\
\hline $\begin{array}{l}\text { Support for } \\
\text { Alignment }\end{array}$ & - Task instruc- & $\begin{array}{l}\text { - in situ com- } \\
\text { munication tool }\end{array}$ \\
& tion & $\begin{array}{l}\text { - in situ aware- } \\
\text { ness tool }\end{array}$ \\
\hline
\end{tabular}

Table 1: Components for supporting crowdsourcing practices.

Additionally, citizensourcing features open participation to encourage anyone to be a crowdsourcer as well as a crowdworker. Therefore, crowdsourcingrelevant tools need to be usable and useful for diverse people, and end-user developable tools could be an important role in this context.

It is also important to find the right crowdworkders. Mechanisms for finding the right crowdworkers may need to consider not only their current location but also their trajectories.

\section{Prototypes and experiences}

We now describe our experiences with the smartphone-based prototypes of the mechanisms for supporting citizensourcing.

\subsection{Exploratory data collection and visualization}

We have developed and tested a mobile phone-based exploratory data collection and visualization environment for citizens, which uses dynamically shared tags to provide social cues and scaffold participants (see Fig. 1) [8]. Research shows that a tag-based exploratory system enables rapid exploration, and possibly provides a kind of scaffolding for learning in Web search [2][5]. We have extended and integrated such tag-based approach in a mobile data collection environment for citizens to support exploration in physical and digital spaces.

As shown in Fig. 1, users can take pictures and add tags to the pictures easily on a smartphone or a tablet PC.

The system supports three types of tag sharing, which allows for flexible integration of the system into the sociotechnical setting of the overall information gathering procedure:

(1) Users exploit a fixed set of tags that someone (e.g., a domain expert) prepares in advance.

(2) Users can create, modify and delete tags in situ, and use them personally.

(3) Users can create, modify and delete tags in situ, and share them with other users.

Users can share the collected photos and tags on a large touch-screen device immediately, as shown in Fig. 2.

Our experiment with this system has shown that the mechanism to create and share tags in situ provides social cues that affect exploratory data collection in different ways. Participants used these social cues to work efficiently by avoiding redundancy, socialize and compete with other participants. Also, it seems that shared tags can support a type of discovery and learning when it is embedded in a right kind of sociotechnical environment and collaboration context. This is in line 
with what existing research shows about exploratory Web search [5].

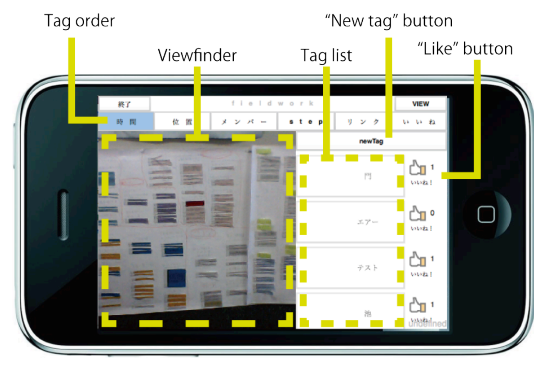

Look for things to record

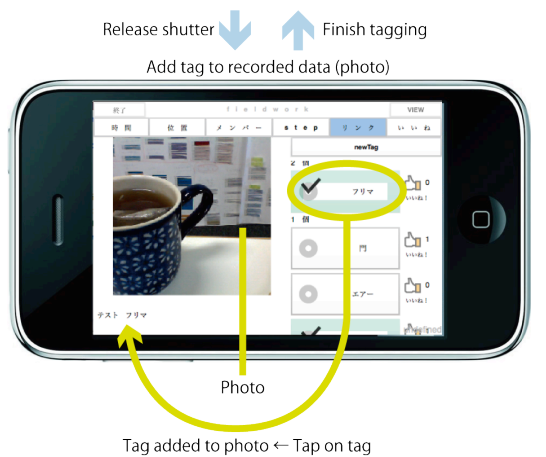

Fig. 1: A mobile phone-based exploratory data collection environment.

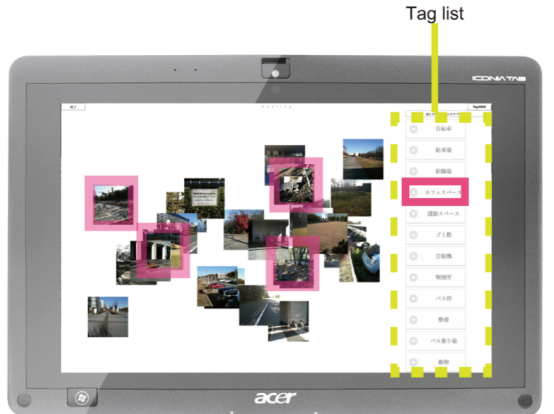

Fig. 2: Interactive visualization of collected data.

\subsection{End-user development}

Given the diversity of citizen population and the complexity of their situations, it is highly desirable to support end-user development of data collection and visualization tools.

To understand the needs and explore the design space for end-user develop- ment of citizensourcing tools, we have built a participatory congestion sensing tool using off-the-shelf smartphones and open-source hardware components [9]. As shown in Fig. 3, a $\mathrm{CO}_{2}$ sensor and a battery are integrated with a bag, which forwards the data to a smart phone via a ZigBee-Bluetooth gateway. The smart phone estimates the congestion level based on the $\mathrm{CO}_{2}$ sensor reading and uploads it to a server along with the current location information.

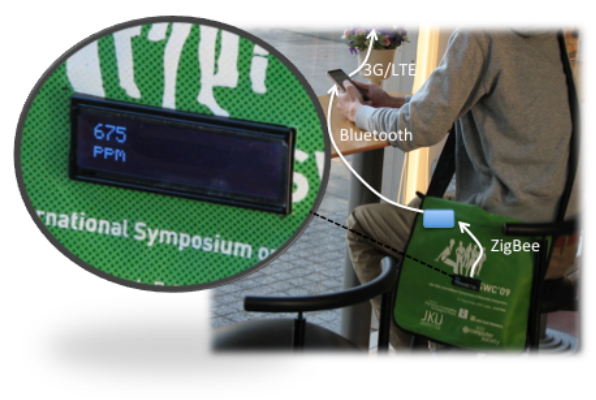

Fig. 3: Participatory congestion sensing tool.

The development process of an open hardware-based citizensourcing tool can be understood a bit differently from traditional context-aware applications. As shown in Table 2, the development process can include Exploration (Step 2) as well as Setup (Step 3) to exploit hardware and data-source components, as well as the other steps that can be supported by existing software architectures (e.g., widget-based [3] or blackboard-based architectures).

\subsection{Repository system for geo-tagged questions}

It is often difficult for a crowdsourcer to define the right information collection task. We have developed a repository system that allows crowdsourcers to share and reuse geo-tagged questions, i.e., core definitions of information collection tasks. Fig. 4 shows the system's user interfaces. 


\begin{tabular}{|l|l|}
\hline $\begin{array}{l}\text { 1. Speci- } \\
\text { fication }\end{array}$ & $\begin{array}{l}\text { Report congestion levels on trains } \\
\text { using smart phones, sensors, and } \\
\text { train-network data }\end{array}$ \\
\hline $\begin{array}{l}\text { 2. Explo- } \\
\text { ration }\end{array}$ & $\begin{array}{l}\text { Use sensors } \mathrm{CO}_{2} \text {, acceleration, etc.) } \\
\text { to capture data on a train. Also, record } \\
\text { congestion levels on the train manual- } \\
\text { ly. Create a model to transform sensor } \\
\text { readings into a congestion level. Addi- } \\
\text { tionally, identify train-network data and } \\
\text { explore ways to exploit them. }\end{array}$ \\
\hline 3. Setup & $\begin{array}{l}\text { Connect a CO }{ }_{2} \text { sensor to a microcon- } \\
\text { troller and a wireless communication } \\
\text { module, and integrate it with a physical } \\
\text { object such as a bag. }\end{array}$ \\
\hline $\begin{array}{l}\text { 4. Acqui- } \\
\text { sition and } \\
\text { delivery }\end{array}$ & $\begin{array}{l}\text { Write software on a smart phone to } \\
\text { obtain data from the CO }{ }_{2} \text { sensor, con- } \\
\text { vert it to a congestion level, and up- } \\
\text { load it to a server along with the cur- } \\
\text { rent location information. }\end{array}$ \\
\hline $\begin{array}{l}\text { 5. Recep- } \\
\text { tion and } \\
\text { action }\end{array}$ & $\begin{array}{l}\text { Smart phone application receives data } \\
\text { from the server and displays conges- } \\
\text { tion levels on a map along with the } \\
\text { train-network information. }\end{array}$ \\
\hline
\end{tabular}

Table 2: Steps for developing the congestion sensing tool.

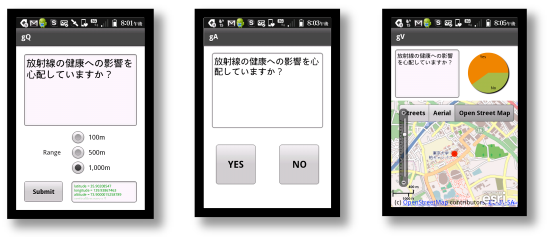

Fig. 4: User interfaces for creating/sharing geo-tagged questions (left) and answers (middle), and for displaying answers (right).

\section{Discussion}

Our experiences with the prototypes show that key mechanisms for supporting citizensourcing can be implemented on smartphones. Citizens can participate in citizensourcing, using the mechanisms for supporting engagement, imagination, and alignment, while they are on the move.

Awareness tools have multi-faceted effect as they provided means for socialization, coordination, discovery and learning, thereby supporting all components in Ta- ble 1. The tools were designed for supporting exploration; however, people appropriated the tools and used them to make their experiences more engaging and to coordinate distributed work. The tools can be improved to support such usage explicitly. These findings, in particular, have significant implications for the design of novel crowd-powered mechanisms.

End-user development of crowdsourcing-related tools can be challenging when it involves hardware development. An interesting approach to address the challenge is to use crowdsourcing here as well (i.e., macrotasking to ask technology experts for help.)

Overall, our experiences suggest that the novelty of citizensourcing lies in its ability to enable broader citizen participation and collection of locally-relevant information.

\section{Conclusion}

In this paper, we have proposed citizensourcing to create a novel crowdpowered mechanism for viewing and imagining urban and public spaces. Our findings suggest the roles of exploration, engagement, and other factors in designing novel crowd-powered mechanisms. Such mechanisms have the potential to influence the ways people experience urban spaces [19] as well.

\section{Acknowledgements}

This research was supported by the Green Network of Excellence Program of MEXT, Japan ("Environmental Information Project") and the Promoting Science and Technology System Reform Program of JST, Japan ("Research and Development of Crisis Management Cloud Systems with Public and Private Cooperation"). 


\section{References}

[1] E. Arias, H. Eden, F. Fischer, A. Gorman, E. Scharff, "Transcending the Individual Human Mind--Creating Shared Understanding through Collaborative Design," $A C M$ Trans. Computer-Human Interaction, 7(1), pp.84-113, 2000.

[2] E.H. Chi, "Information Seeking Can Be Social," IEEE Computer, March, pp.42-46, 2009.

[3] A.K. Dey, G.D. Abowd, D. Salber, "A Conceptual Framework and a Toolkit for Supporting the Rapid Prototyping of Context-Aware Applications," Human-Computer Interaction, 16:2-4, pp.97-166, 2001.

[4] S. Elwood, M.F. Goodchild, D.Z. Sui, "Researching Volunteered Geographic Information: Spatial Data, Gographic Research, and New Social Practice," Annals of the Association of American Geographers, 102(3), pp.571-590, 2012.

[5] Y. Kammerer, R. Nairn, P. Pirolli, E.H. Chi, "Signpost from the Masses: Learning Effects in an Explotaroty Social Tag Search Browser," Proc. CHI'09, pp.625-634, 2009.

[6] S. Kim, C. Robson, T. Zimmerman, J. Pierce, E.M. Haber, "Creek Watch: Pairing Usefulness and Usability for Successful Citizen Science," Proc. CHI'11, pp.2125-2134, 2011.

[7] A. Kittur, S. Khamkar, P. André, R.E. Kraut, "CrowdWeaver: Visually Managing Complex Crowd Work," Proc. CSCW'12, pp.1033-1036, 2012.

[8] S. Konomi, T. Sasao, M. Arikawa, H. Fujita, "A Mobile Phone-Based Exploratory Citizen Sensing Environment," Proc. Int. Workshop Human Interfaces for Civic and Urban Engagement, pp.745-748, 2013.

[9] S. Konomi, K. Shoji, W. Ohno, "Rapid Development of Civic Computing Services: Opportunities and Challenges," Proc. Int. Conf. Human-
Computer Interaction, pp.309-315, 2013.

[10] A. Kulkarni, M. Can, B. Hartmann, "Collaboratively Crowdsourcing Workflows with Turkomatic," Proc. ACM CSCW'12, pp.1003-1012, 2012.

[11] I.S. Mayer, E.M.V. Bueren, P.W.G. Bots, H.V.D. Voort, R. Seijdel, "Collaborative Decision-making for Sustainable Urban Renewal Projects: A Simulation - Gaming Approach," Environment and Planning B: Planning and Design, 32(3), pp.403-423, 2005.

[12] V.D. Mea, E. Maddalena, S. Mizzaro, "Crowdsourcing to Mobile Users : A Study of the Role of Platforms and Tasks," Proc. DBCrowd 2013: First VLDB Workshop on Databases and Crowdsourcing, pp. 14-19, 2013

[13] MTurk. http://www.mturk.com

[14] H.W. Rittel, Diemmas in a General Theory of Planning, Policy Sciences, 4, pp.155-169, 1973.

[15] L. Suchman, Plans and Situated Actions: The Problem of Humanmachine Communication. Cambridge University Press, 1987.

[16] Wenger, E. Communities of Practice, Cambridge University Press, 1998.

[17] W. Willett, P. Aoki, N. Kumar, S. Subramanian, A. Woodruff, "Common Sense Community: Scaffolding Mobile Sensing and Analysis for Novice Users," Proc. Pervasive'10, pp.301-318, 2010.

[18] W. Willett, J. Heer, M. Agrawala, "Strategies for Crowdsourcing Social Data Analysis," Proc. CHI '12, pp.227-236, 2012.

[19] A. Williams, P. Dourish, "Imagining the City: The Cultural Dimensions of Urban Computing," IEEE Computer, pp.38-43, 2006.

[20] M. Vukovic, S. Kumara, O. Greenshpan, "Ubiquitous Crowdsourcing," In Proc. Adjunct Proc. Ubicomp '10, p. 523, 2010. 